\title{
Rapid-Freeze-Quench Magnetic Circular Dichroism of Intermediate X in Ribonucleotide Reductase: New Structural Insight
}

\author{
Nataša Mitic, ${ }^{\dagger}$ Lana Saleh, ${ }^{\ddagger}$ Gerhard Schenk, ${ }^{\dagger}$ J. Martin Bollinger, Jr., ${ }^{*,}$ and Edward I. Solomon ${ }^{\star, \dagger}$ \\ Department of Chemistry, Stanford University, 333 Campus Street, Stanford, California 94305, and Department of \\ Biochemistry and Molecular Biology, The Pennsylvania State University, University Park, Pennsylvania 16802
}

Received June 7, 2003; E-mail: Edward.Solomon@stanford.edu

Binuclear, non-heme iron-containing proteins, including the R2 subunit of ribonucleotide reductase (RNR), ${ }^{1}$ methane monooxygenase hydroxylase $(\mathrm{MMOH}){ }^{2,3}$ and stearoyl acyl carrier protein $\Delta^{9}-$ desaturase $\left(\Delta^{9} \mathrm{D}\right),{ }^{4}$ all contain similar carboxylate/histidinecoordinated diiron active sites that are responsible for dioxygen activation and mediation of a broad spectrum of oxidation reactions. Whereas oxygen activation by $\mathrm{MMOH}$ leads to the hydroxylation of methane to methanol, in R2 it leads to a one-electron oxidation of an endogenous tyrosine residue (Y122). ${ }^{5}$ The latter reaction produces the tyrosyl radical $\left(\mathrm{Y}_{122^{\circ}}\right)$ in $\mathrm{R} 2$ that is necessary for ribonucleotide reduction by the RNR holoenzyme $(\mathrm{R} 1 \cdot \mathrm{R} 2)$ complex. High-valent oxygen intermediates have been trapped in the reactions of $\mathrm{MMOH}$ (compound $\mathbf{Q}$ which is thought to be an $\mathrm{Fe}_{2}{ }^{(\mathrm{IV})} \mathrm{O}_{2}$ bis$\mu$-oxo diamond core) ${ }^{6}$ and $\mathrm{R} 2$ (intermediate $\mathbf{X},{ }^{7}$ an oxo-bridged $\mathrm{Fe}^{(\mathrm{IV})} \mathrm{Fe}^{(\mathrm{III})}$ species, formally the one-electron reduced form of $\mathbf{Q}$ ). Intermediate $\mathrm{X}$ is responsible for the oxidation of Y122 to the radical, which is approximately $5.3 \AA$ away from the diiron cluster. ${ }^{8}$ Earlier spectroscopic studies (by stopped-flow measurements, ${ }^{7,9}$ EPR,${ }^{10}$ Mössbauer,${ }^{10}$ ENDOR,${ }^{11-13}$ and EXAFS ${ }^{14}$ ) have indicated that $\mathbf{X}$ is a spin-coupled $\mathrm{Fe}^{(\mathrm{IV})} \mathrm{Fe}^{(\mathrm{III})}$ center with one or two $\mu$-oxo bridges present.

To elucidate the geometric and electronic structure of intermediate $\mathbf{X}$, a protocol has been developed to perform low-temperature magnetic circular dichroism (LT-MCD) measurements on a strain free optical sample generated by using the rapid-freeze-quench (RFQ) method (see Supporting Information). This study examines the electronic and structural properties of $\mathbf{X}$ in the double mutant $\mathrm{Y} 122 \mathrm{~F} / \mathrm{Y} 356 \mathrm{~F}$ of R2 by variable-temperature, variable-field MCD (VTVH MCD), combined with LT-absorption, EPR, and ligand field (LF) calculations, allowing us to distinguish between the bis$\mu$-охо, $\mu$-охо, and other bridge possibilities for the active site structure of the important intermediate.

MCD data were collected on the double mutant R2-Y122F/ $\mathrm{Y} 356 \mathrm{~F}$, in which up to 1.4 equiv of $\mathbf{X}$ can be accumulated due to its favorable kinetics. ${ }^{15}$ These first measurements of the MCD spectrum of $\mathbf{X}$ were enabled by our novel RFQ-MCD methodology, modified from the method used to trap the native intermediate in the multicopper oxidases. ${ }^{16}$ RFQ was carried out as described in previous R2 studies $^{9}$ (see Supporting Information). Intermediate $\mathbf{X}$ was quantified in all samples by EPR spectroscopy (see Supporting Information).

The LT absorption and MCD spectra of intermediate $\mathbf{X}$ in R2$\mathrm{Y} 122 \mathrm{~F} / \mathrm{Y} 356 \mathrm{~F}$ are displayed in Figure 1. The LT MCD spectrum of $\mathbf{X}$ in wt R2 is very similar. ${ }^{17}$ Past studies have reported only a broad absorption feature at $\sim 27800 \mathrm{~cm}^{-1}$ for $\mathbf{X}\left(\epsilon \approx 2700 \mathrm{M}^{-1}\right.$ $\left.\mathrm{cm}^{-1}\right){ }^{7}$ The $10 \mathrm{~K}$ absorption spectrum consists of a weak, broad feature centered at $\sim 20000 \mathrm{~cm}^{-1}\left(\epsilon \approx 900 \mathrm{M}^{-1} \mathrm{~cm}^{-1}\right)$, and two major bands in the UV region at $\sim 27700 \mathrm{~cm}^{-1}\left(\epsilon \approx 2800 \mathrm{M}^{-1}\right.$

$\dagger$ Stanford University

¥ The Pennsylvania State University.

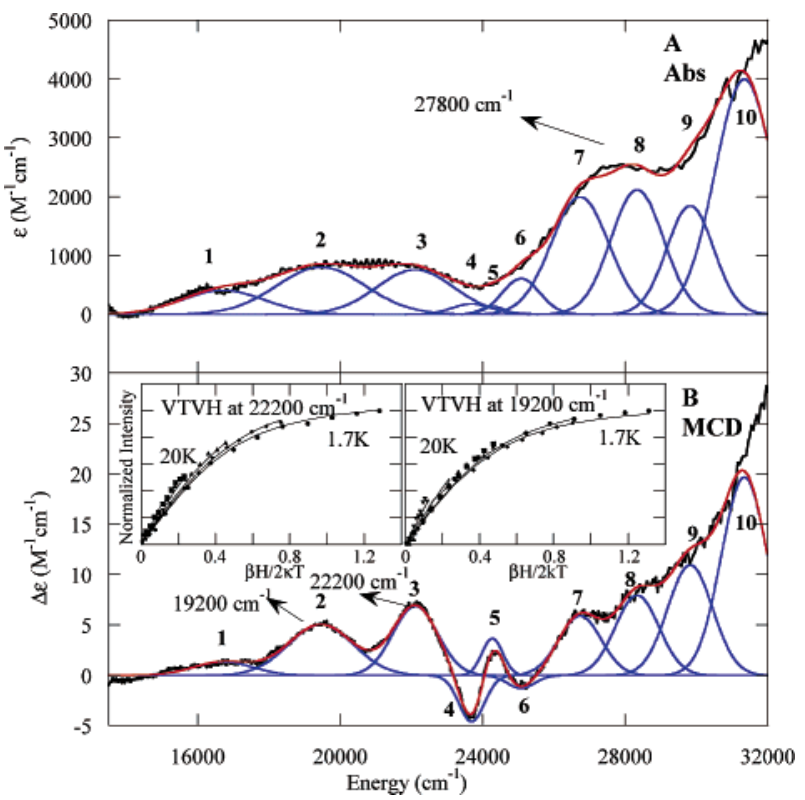

Figure 1. Intermediate R2-Y122F/Y356F-X (A) Gaussian resolved $10 \mathrm{~K}$ absorption spectrum and (B) Gaussian resolved 1.7 K, 7 T RFQ-MCD spectrum (insets showing VTVH MCD data and ground-state $S=1 / 2$ fits at 450 and $520 \mathrm{~nm}$ at $1.7,3.0,5.0,10$, and $20 \mathrm{~K}$ ).

$\left.\mathrm{cm}^{-1}\right)$ and $\sim 31000 \mathrm{~cm}^{-1}\left(\epsilon \approx 4000 \mathrm{M}^{-1} \mathrm{~cm}^{-1}\right)$. Low-temperature MCD data demonstrate that the broad absorption features can be resolved into at least 10 electronic transitions. Simultaneous Gaussian fitting of the LT-Abs and LT-MCD spectra for $\mathbf{X}$ (Figure 1 ) is summarized in Table S1 (see Supporting Information). The ratio of the relative band intensities observed in $\operatorname{MCD}\left(C_{0}\right)$ and absorption spectra $\left(D_{0}\right)$ is used to differentiate metal-based ligand field (LF) and charge transfer (CT) transitions.

The electronic spectrum of valence localized $\mathbf{X}$ identifies three regions from 12000 to $32000 \mathrm{~cm}^{-1}$ based upon the $C_{0} / D_{0}$ ratios: (1) broad, low-energy bands 1-3 at 16 700, $19400,22100 \mathrm{~cm}^{-1}$ with large $C_{0} / D_{0}$ ratios $(0.12-0.50)$ are $\mathrm{d}-\mathrm{d}$ in character with low associated absorption intensity and are the first spin-allowed LF transitions of an $\mathrm{Fe}^{(\mathrm{IV})}$ to be observed (all $\mathrm{Fe}^{(\mathrm{III})} \mathrm{d}-\mathrm{d}$ transitions are spin-forbidden and weak even in exchange-coupled systems), (2) sharp and weak bands 4 and 5, which represent $\Delta S=1$ spinflip transitions within the $\mathrm{Fe}^{(\mathrm{IV})}$, and (3) bands $6-10$, which have low $C_{0} / D_{0}$ ratios $(0.004-0.011)$ and are assigned to oxo $\rightarrow \mathrm{Fe}^{(\mathrm{IV})}$ $\mathrm{CT}$ transitions. The $\mathrm{LF}(\mathrm{d} \rightarrow \mathrm{d})$ transitions have higher $C_{0} / D_{0}$ ratios as compared to the CT transitions because they are centered on the $\mathrm{Fe}^{(\mathrm{IV})}$ atom with a much higher spin-orbit coupling constant $\left(\xi_{\mathrm{Fe}}{ }^{(\mathrm{IV})}=520 \mathrm{~cm}^{-1}\right)$ than the oxo group $\left(\xi_{\mathrm{O}}=60-70 \mathrm{~cm}^{-1}\right)$. Spinorbit coupling leads to the excited state mixing responsible for $C$-term intensity.

10.1021/ja036556e CCC: $\$ 25.00$ @ 2003 American Chemical Society 


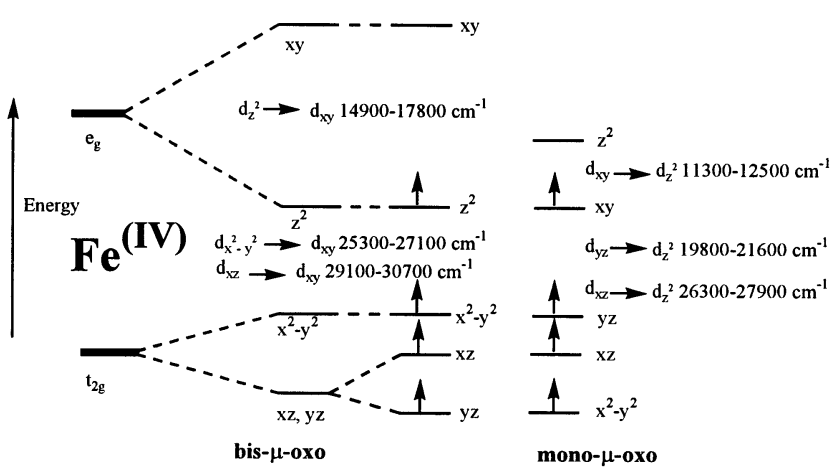

Figure 2. Ligand field splitting diagram indicating $\mathrm{d}-\mathrm{d}$ transitions and their calculated energies for $\mathrm{Fe}^{(\mathrm{IV})}$ in bis- $\mu$-oxo and mono- $\mu$-oxo environments.

It is important to note that the VTVH MCD data (inset in Figure 1) give the same spin Hamiltonian parameters as the ground-state EPR signal $(S=1 / 2)$ for intermediate $\mathbf{X}$, which confirms that these are associated with the same species. With respect to the ground state, there has been some debate concerning the localization of the oxidation on the iron center versus the oxo bridge. The large $C_{0} / D_{0}$ ratios for the LF region $(0.12-0.50$, which is $4-5$ times larger than for the $\mathrm{CT}$ region $)^{18}$ strongly support significant $\mathrm{Fe}^{(\mathrm{IV})}$ character in the paramagnetic center of $\mathbf{X}$.

Previous LF analyses of the isoelectronic $\mathrm{Mn}^{(\mathrm{III})}$ ion in $\mu$-oxo ${ }^{19,20}$ and bis- $\mu$ - $\mathrm{Oxo}^{21}$ environments are used as a basis for the analysis of the MCD data for the $\mathrm{Fe}^{(\mathrm{IV})}$ site in intermediate $\mathbf{X}$. High-spin octahedral $\mathrm{Fe}^{(\mathrm{IV})}\left(3 \mathrm{~d}^{4}\right.$ configuration) has four of the five $\mathrm{d}$ orbitals half-occupied and only one spin-allowed $d-d$ transition $\left({ }^{5} E_{g} \rightarrow\right.$ ${ }^{5} \mathrm{~T}_{2 \mathrm{~g}}$ ). However, the reduced symmetry of the site (dominating due to the strong oxo bridge(s)) leads to more than one spin-allowed $\mathrm{d}-\mathrm{d}$ transition. Figure 2 shows the inferred d-orbital splitting pattern for $\mathrm{Fe}^{(\mathrm{IV})}$ in both mono- $\mu$-oxo and bis- $\mu$-oxo environments. The presence of a single oxo bridge lifts the degeneracies of the five $\mathrm{d}$ orbitals of $\mathrm{Fe}^{(\mathrm{IV})}$, leaving the $\mathrm{d}_{z}{ }^{2}$ orbital unoccupied ( $z$ axis is oriented toward the $\mathrm{Fe}-\mathrm{O}$ bond), while for the bis- $\mu$-oxo case the $\mathrm{d}_{x y}$ is the highest unoccupied orbital (the two oxo bridges define the $x y$ plane). We combine the spectral RFQ-MCD data for $\mathbf{X}$ with LF calculations to predict the splitting pattern of d-orbital energies for the $\mathrm{Fe}^{(\mathrm{IV})}$ center for both the mono- $\mu$-oxo and the bis- $\mu$-oxo possible structures of intermediate $\mathbf{X}$.

The d-orbital energy levels and wave functions were calculated using the method of Companion and Komarynsky. ${ }^{22}$ Ligand field radial parameters $\left(\alpha_{2}\right.$ and $\left.\alpha_{4}\right)$ are obtained experimentally using crystallographically characterized octahedral Mn model complexes. ${ }^{23-26}$ A range of $\alpha_{2}$ and $\alpha_{4}$ were used to predict the shift in energies of $\mathrm{d}-\mathrm{d}$ transitions for $\mathrm{Fe}^{(\mathrm{IV})}$ relative to $\mathrm{Mn}^{(\mathrm{III})}$ for both mono- $\mu$-oxo and bis- $\mu$-oxo bridged dimers (see Supporting Information). Because of the increased $Z_{\text {eff }}$ in $\mathrm{Fe}^{(\mathrm{IV})}, \mathrm{d}-\mathrm{d}$ transitions are expected to shift to higher energies relative to those observed for $\mathrm{Mn}^{(\mathrm{III})}$. Calculated $\mathrm{d}-\mathrm{d}$ transition energies for $\mathrm{Fe}^{(\mathrm{IV})}$ ( $\mathbf{X}$ having mono- $\mu$-oxo and bis- $\mu$-oxo structures) are shown in Table S5 (see Supporting Information). For a range of $\alpha_{2}$ values (10-20\% increase) and $\alpha_{4}(40-50 \%$ increase) in going from a trivalent to a tetravalent metal center, ${ }^{27,28} \mathrm{Fe}^{(\mathrm{IV})} \mathrm{d}-\mathrm{d}$ transition energies for a mono- $\mu$-oxo bridged structure are relatively low as compared to the bis- $\mu$-oxo structure (transition energies at 11500,19800 , and $26300 \mathrm{~cm}^{-1}$ as compared to 14900,25300 , and $29100 \mathrm{~cm}^{-1}$ ). The three LF bands at 16700,19500 , and $22100 \mathrm{~cm}^{-1}$, observed for $\mathbf{X}$ (Figure 1), are all low-energy transitions. ${ }^{29}$ This is consistent with the mono- $\mu$-oxo but not bis- $\mu$-oxo structure for $\mathbf{X}$. The bis$\mu$-oxo structure is predicted to have transitions at much higher energy than observed, because the bis-oxo LF greatly destabilizes the $\mathrm{d}_{x y}$ acceptor orbital.

In summary, we present the first RFQ-MCD data on the transient, high-valent iron-oxo intermediate $\mathbf{X}$. $\mathrm{Fe}^{(\mathrm{IV})} \mathrm{LF}$ transitions are observed for the first time. The spin-allowed $\mathrm{Fe}^{(\mathrm{IV})} \mathrm{d} \rightarrow \mathrm{d}$ transitions are analyzed using LF theory based on our past studies on isoelectronic $\mathrm{Mn}^{\text {(III) }}$ sites in mono- $\mu$-oxo and bis- $\mu$-oxo environments. The analysis favors the mono- $\mu$-oxo model for $\mathbf{X}$, where the reductive cleavage of the $\mathrm{O}-\mathrm{O}$ bond generates an oxo bridge and $\mathrm{H}_{2} \mathrm{O}$.

Acknowledgment. This work is supported by NSF MCB 9816051 (E.I.S.) and Public Health Services GM 55365 (J.M.B.).

Supporting Information Available: One table with electronic transition energies, MCD, LT-Abs, Gaussian fit intensities, and $C_{0} / D_{0}$ ratios for $\mathbf{X}$, four tables with LF parameters used in calculations, experimental and predicted d-orbital energy levels, experimental and calculations details, EPR spectra (PDF). This material is available free of charge via the Internet at http://pubs.acs.org.

\section{References}

(1) Stubbe, J. J. Biol. Chem. 1990, 265, 5329-5332

(2) Merkx, M.; Kopp, D. A.; Sazinsky, M. H.; Blazyk, J. L.; Müeller, J.; Lippard, S. J. Angew. Chem., Int. Ed. 2001, 40, 2782-2807.

(3) Wallar, B. J.; Lipscomb, J. D. Chem. Rev. 1996, 96, 2625-2657.

(4) Broadwater, J. A.; Haas, J. A.; Fox, B. G. Fett/Lipid 1998, 100, 103113

(5) Stubbe, J. Nature 1994, 370, 502.

(6) Shu, L. J.; Nesheim, J. C.; Kauffmann, K.; Münck, E.; Lipscomb, J. D.; Que, L., Jr. Science 1997, 275, 515-518.

(7) Bollinger, J. M., Jr.; Edmondson, D. E.; Huynh, B. H.; Filley, J.; Norton, J. R.; Stubbe, J. Science 1991, 253, 292-298.

(8) Nordlund, P.; Sjöberg, B. M.; Eklund, H. Nature 1990, 345, 593-598

(9) Ravi, N.; Bollinger, J. M., Jr.; Huynh, B. H.; Edmondson, D. E.; Stubbe J. J. Am. Chem. Soc. 1994, 116, 8007-8014.

(10) Krebs, C.; Baldwin, J.; Chen, S. X.; Ley, B. A.; Edmondson, D. E.; Bollinger, J. M., Jr.; Huynh, B. H. J. Inorg. Biochem. 1999, 74, 195

(11) Willems, J. P.; Lee, H. I.; Burdi, D.; Doan, P. E.; Stubbe, J.; Hoffman, B. M. J. Am. Chem. Soc. 1997, 119, 9816-9824.

(12) Sturgeon, B. E.; Burdi, D.; Chen, S. X.; Huynh, B. H.; Edmondson, D. E.; Stubbe, J.; Hoffman, B. M. J. Am. Chem. Soc. 1996, 118, 75517557.

(13) Burdi, D.; Willems, J. P.; Riggs-Gelasco, P. J.; Antholine, W. E.; Stubbe, J.; Hoffman, B. M. J. Am. Chem. Soc. 1998, 120, 12910-12919.

(14) Riggs-Gelasco, P. J.; Shu, L. J.; Chen, S. X.; Burdi, D.; Huynh, B. H.; Que, L., Jr.; Stubbe, J. J. Am. Chem. Soc. 1998, 120, 849-860.

(15) Saleh, L.; Bollinger, J. M., Jr., unpublished results.

(16) Lee, S. K.; George, S. D.; Antholine, W. E.; Hedman, B.; Hodgson, K. O.; Solomon, E. I. J. Am. Chem. Soc. 2002, 124, 6180-6193.

(17) Mitić, N.; Solomon, E. I., unpublished results.

(18) Lehnert, N.; Neese, F.; Ho, R. Y. N.; Que, L., Jr.; Solomon, E. I. J. Am. Chem. Soc. 2002, 124, 10810-10822.

(19) Brunold, T. C.; Gamelin, D. R.; Stemmler, T. L.; Mandal, S. K.; Armstrong, W. H.; Penner-Hahn, J. E.; Solomon, E. I. J. Am. Chem. Soc. 1998, 120, 8724-8738.

(20) Brunold, T. C.; Gamelin, D. R.; Solomon, E. I. J. Am. Chem. Soc. 2000, $122,8511-8523$.

(21) Gamelin, D. R.; Kirk, M. L.; Stemmler, T. L.; Pal, S.; Armstrong, W. H.; Penner-Hahn, J. E.; Solomon, E. I. J. Am. Chem. Soc. 1994, 116, 23922399.

(22) Companion, A. L.; Komarynsky, M. A. J. Chem. Educ. 1964, 41, $257-$ 262.

(23) Zaitseva, E. G.; Baidina, I. A.; Stabnikov, P. A.; Borisov, S. V.; Igumenov, I. K. Zh. Strukt. Khim. 1990, 31, 184-189.

(24) Goodson, P. A.; Oki, A. R.; Glerup, J.; Hodgson, D. J. J. Am. Chem. Soc. 1990, 112, 6248-6254.

(25) Wieghardt, K.; Bossek, U.; Ventur, D.; Weiss, J. J. Chem. Soc., Chem Commun. 1985, 347-349.

(26) Pal, S.; Gohdes, J. W.; Wilisch, W. C. A.; Armstrong, W. H. Inorg. Chem 1992, 31, 713-716

(27) Jørgensen, C. K. Acta Chem. Scand. 1955, 9, 1362-1377.

(28) Jørgensen, C. K. Acta Chem. Scand. 1957, 11, 73-85.

(29) Note that the lowest energy transition is within the split ${ }^{5} \mathrm{E}$ set of orbitals and shows large shifts in energy in Mn(III) complexes due to differences in Jahn-Teller tetragonal distortions.

JA036556E 